\title{
Eksplorasi Etnomatematika Pada Candi Agung Gumuk Kancil Banyuwangi Sebagai Lembar Kerja Siswa
}

Author:
Marenda Dias Krismonita ${ }^{1}$
Sunardi ${ }^{2}$
Erfan Yudianto $^{3}$
Affiliation:
1,2,3 University of Jember, East
Java, Indonesia
Corresponding author:
Marenda Dias Krismonita,
Marendadiask@ gmail.com
Dates:
Received: $13 / 6 / 2021$
Accepted: $15 / 7 / 2021$
Published: $23 / 7 / 2021$

\section{Author:}

Marenda Dias Krismonita ${ }^{1}$

Sunardi ${ }^{2}$

Affiliation:

${ }^{1,2,3}$ University of Jember, East

Java, Indonesia

\section{Corresponding author:}

Marenda Dias Krismonita, Marendadiask@gmail.com

\section{Dates:}

Accepted: $15 / 7 / 2021$

Published: 23/7/2021

\begin{abstract}
Abstrak. Etnomatematika adalah matematika yang ditemukan dalam budaya masyarakat yang tanpa sadar telah menerapkan konsep matematika dalam budayanya. Tujuan dari penelitian kualitatif dengan pendekatan etnografi ini adalah untuk mendeskripsikan etnomatematika pada bangunan Candi Agung Gumuk Kancil. Subjek penelitian ini adalah satu orang penjaga candi, satu orang masyarakat yang paham tentang sejarah pembangunan candi dan satu orang yang terbiasa memugar candi. Metode pengumpulan data yang digunakan adalah observasi, wawancara dan dokumentasi. Hasil penelitian ini menunjukkan adanya etnomatematika pada bangunan Candi Agung Gumuk Kancil. Unsur geometri yang ditemukan meliputi: bangun datar (segitiga, persegi, persegi panjang, dan lingkaran), bangun ruang (kubus, balok, dan tabung), kesebangungan, kekongruenan, dan transformasi geometris (translasi dan refleksi). Etnomatematika pada penelitian ini akan dibuat LKS dengan materi bangun ruang sisi lengkung untuk kelas IX semester genap.
\end{abstract}

Kata kunci: Etnomatematika, Candi Agung, Geometri

\begin{abstract}
Ethnomatematics is mathematics that is found in the culture of a society that has unknowingly applied the concept of mathematics in its culture. The purpose of this qualitative research with an ethnographic approach is to describe ethnomatematics in the Great Gumuk Kancil Temple building. The subjects of this study were one temple guard, one community member who understood the history of temple construction and two people who were accustomed to restoring the temple. Data collection methods used were observation, interview and documentation. The results of this study indicate the existence of ethnomatematics in the Great Gumuk Kancil Temple building. Geometry elements found include: flat shapes (triangles, squares, rectangles and circles), geometric shapes (cubes, beams, and tubes), kebebangungan, concordance, and geometric transformations (translation and reflection). Ethnomatematics in this study will be made LKS with curved side space material for class IX second semester.
\end{abstract}

Keywords: Ethnomatematic, Great Temple, Geometry

\section{JoMEaL}

Copyright:

This work is licensed under a Creative Commons Attribution-ShareAlike 4.0 International License.

Read online:

https://jurnal.unej.ac.id/index.php/JOMEAL/index or scan barcode beside.

How to cite this article:

Krismonita, M., Sunardi, S., \& Yudianto, E. (2021). Eksplorasi Etnomatematika pada Candi Agung Gumuk Kancil Banyuwangi sebagai Lembar Kerja Siswa. Journal of Mathematics Education and Learning, 1(2), 149-158. Retrieved from https://jurnal.unej.ac.id/index.php/JOMEAL/article/view/24327 


\section{Pendahuluan}

Matematika adalah ilmu yang dipelajari dalam berbagai jenjang pendidikan dari taman kanakkanak hingga perguruan tinggi. Matematika dapat diaplikasikan dalam berbagai hal yang berkaitan dengan kehidupan sehari-hari, misalnya transaksi perdagangan, kegiatan pertukangan, dan pengukuran. Bagi beberapa siswa matematika sering dianggap ilmu yang sukar dipelajari (Rani, 2018; Asnawati \& Dewi, 2019; ). Oleh karena itu perlunya proses pembelajaran yang inovatif. Pemberian contoh tentang keterkaitan matematika dalam kehidupan sehari-hari diharapkan mampu memudahkan siswa dalam memahami pengetahuan tentang matematika. Semakin jauh suatu materi pendidikan dari kebudayaan maka akan semakin susah pula materi dipahami oleh peserta didik. Diperlukan suatu pendekatan yang dapat menghubungkan antara matematika dengan unsur kebudayaan sekitar (Wahyuni, 2013). Budaya merupakan seluruh aspek kehidupan masyarakat yang diperoleh dari tingkah laku, pola pikir, dan cara belajar. Studi tentang matematika dalam budaya dinamakan etnomatematika.

Etnomatematika adalah budaya atau kebiasan dalam kehidupan masyarakat yang mengandung konsep atau unsur matematika. Pemberian bahan pembelajaran berbasis etnomatematika diharapkan mampu membuat siswa lebih mengenal budaya dan mempermudah dalam memahami pengetahuan matematika. Salah satu budaya yang mengandung etnomatematika adalah Candi Agung Gumuk Kancil Banyuwangi. Bagian-bagian komponen candi yang unik dapat dijadikan sebagai media pembelajaran matematika pada bidang geometri di sekolah. Beberapa objek tersebut adalah bangunan dan ukiran pada bangunan candi. Tujuan penelitian ini adalah mendeskripsikan etnomatematika pada Candi Agung Gumuk Kancil sebagai bahan pembelajaran matematika dan menyusun produk hasil penelitian berupa ringkasan lembar kerja siswa yang berkaitan dengan etnomatematika pada Candi Agung Gumuk Kancil.

\section{Metode Penelitian}

Penelitian ini adalah penelitian kualitatif dengan pendekatan etnografi. Pendekatan etnografi digunakan untuk menggambarkan, menjelaskan dan menganalisis konsep atau unsur geometri yang terdapat pada bangunan Candi Agung Gumuk Kancil. Lokasi penelitian berada di Dusun Wonoasih, Desa Bumiharjo, Kecamatan Glenmore, Kabupaten Banyuwangi. Fokus penelitian ini adalah bentuk bangunan Candi Agung Gumuk Kancil. Subjek dalam penelitian ini adalah satu orang penjaga candi, satu orang masyarakat yang paham tentang sejarah pembangunan candi, dan satu orang yang terbiasa memugar candi.

Prosedur penelitian dilakukan dengan beberapa langkah. Pertama, pemilihan lokasi dan subjek penelitian. Kedua, pembuatan instrumen penelitian sebagai pedoman observasi dan wawancara. Ketiga, validasi draft instrumen penelitian yang divalidasi oleh dua dosen pendidikan matematika. Keempat, pengumpulan data melalui observasi, wawancara dan dokumentasi. Observasi dilakukan dengan mengamati secara keseluruhan bentuk geometri bangunan Candi Agung Gumuk Kancil. Wawancara dilakukan untuk memperoleh data yang lebih mendalam tentang bangunan Candi Agung Gumuk Kancil sehingga dapat memperkuat hasil observasi. Langkah selanjutnya adalah analisis data, langkah ini dilakukan dengan menyusun data sesuai dengan fokus kajian masalah dan tujuan penelitian. Langkah berikutnya yaitu pembuatan Lembar Kerja Siswa (LKS) bab bangun ruang sisi lengkung (tabung) pada bangunan Candi Agung Gumuk Kancil. Langkah terakhir adalah kesimpulan, peneliti melakukan penarikan kesimpulan dari hasil analisis data yang telah diperoleh pada tahap sebelumnya. 


\section{Hasil dan Pembahasan}

Etnomatematika telah banyak ditemukan sebelumnya. Menurut Wahyu (S. Wahyu, 2018) pada bangunan Pura Mandara Giri Semeru Agung memiliki unsur-unsur matematika, yakni kekongruenan, kesebangunan, bangun ruang sisi datar, transformasi geometri (refleksi, translasi, rotasi). Kemudian menurut Rahmawati (Rahmawati, 2019) yang meneliti gapura GESIBU Blambangan yang memiliki bentuk mengadopsi dari Candi Angka Tahun Panataran yang terletak di Blitar. Gapura GESIBU Blambangan memiliki unsur-unsur matematika berupa bangun datar yaitu trapesium dan persegi panjang, bangun ruang yaitu balok, limas segiempat terpancung, dan setengah tabung, transformasi geometri yaitu refleksi, translasi, rotasi, serta barisan aritmatika.

Menurut Zuhry (2018) Candi merupakan bangunan yang memiliki beberapa fungsi diantaranya sebagai tempat pemujaan dan pendarmaan seorang raja. Candi diartikan sebagai sebuah bangunan yang memiliki arsitektur dan struktur kerajaan hindu dan budha. Candi Agung Gumuk Kancil terletak di Dusun Wonoasih, Desa Bumiharjo, Kecamatan Glenmore, Kabupaten Banyuwangi. Hingga saat ini, candi ini difungsikan sebagai tempat pemujaan. Ciri dari candi ini adalah arsitektur perpaduan dari Jawa dan Bali. Berdasarkan informasi dari informan, Pembangunan candi terinspirasi dari Candi Angka Tahun yang berada di komplek Candi Penataran Blitar. Hal tersebut ditunjukkan dengan bentuk badan dan atap candi Gumuk Kancil yang sebanding dengan konsep bangunan yang dimiliki oleh Candi Angka Tahun. Candi Agung Gumuk Kancil memiliki tiga bagian yaitu dasar, badan, dan puncak. Berikut merupakan gambar bentuk bangunan Candi Agung Gumuk Kancil.

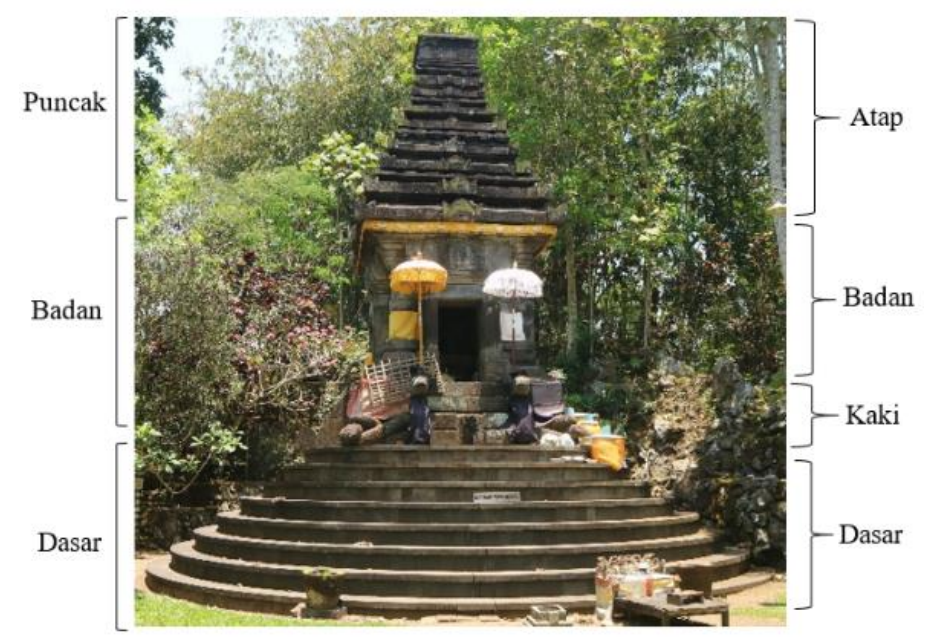

Gambar 1. Candi Agung Gumuk Kancil

Di kompleks Candi Agung Gumuk Kancil, terdapat bangunan yang dinamakan Lembu Nandini. Letaknya di depan Candi Agung Gumuk Kancil sejauh 17 meter ke arah selatan dengan posisi saling berhadapan. Secara keseluruhan, bentuk dasar candi bagian bawah (lingkaran) dan bagian atas (bujur sangkar) sama dengan Candi Agung Gumuk Kancil. 


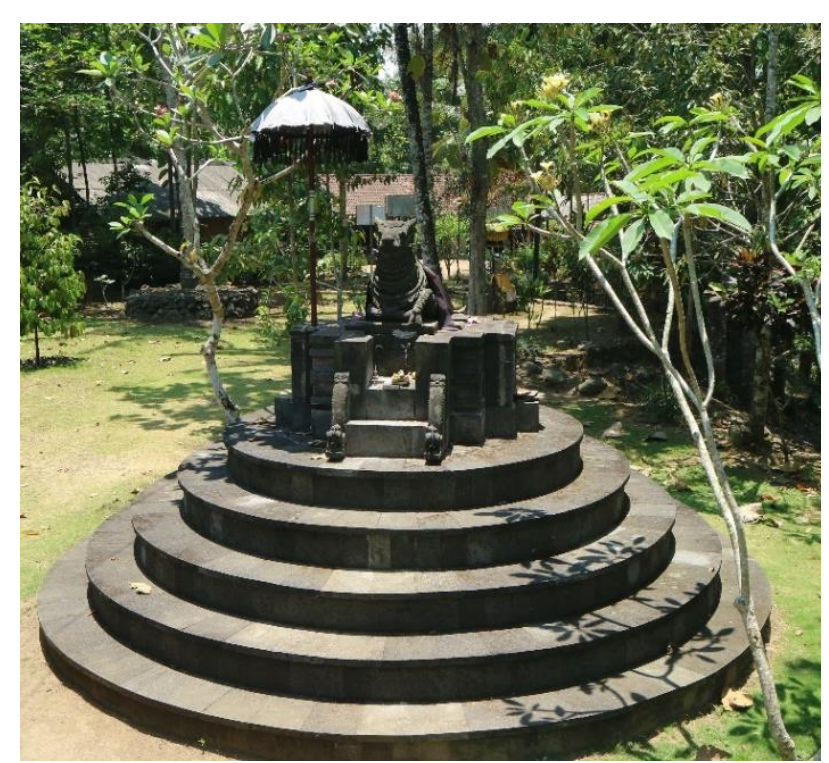

Gambar 2. Lembu Nandini

Etnomatematika yang ditemukan pada Gambar 1 dan Gambar 2 unsur matematika seperti bangun datar, bangun ruang, kesebangunan, kekongruenan, transformasi geometri (refleksi dan translasi), dan barisan aritmatika.

\section{Bentuk Geometri Bidang dan Ruang}

Bangun datar adalah bangun dua dimensi. Unsur matematika bangun datar terdapat pada setiap komponen candi bagian atap terdiri dari persegi panjang, badan terdiri dari segitiga, segilima, trapesium pada dindingnya dan didominasi oleh persegi panjang. Bangun ruang sisi datar adalah kelompok bangun ruang yang memiliki bagian sisi yang berupa bangun datar. Bangun ruang sisi lengkung adalah kelompok bangun ruang yang memiliki bagian-bagian yang berbentuk lengkungan. Unsur matematika bangun ruang terdapat pada candi apabila diamati dalam dimensi tiga pada atap, badan dan kaki candi didominasi oleh balok, bagian dasar terdiri dari tabung. Bangun datar dan bangun ruang pada Candi Agung Gumuk Kancil disajikan pada Tabel 1.

Tabel 1. Bentuk geometri Bidang dan Ruang

\begin{tabular}{|c|c|c|c|}
\hline Nama & Gambar & Ilustrasi & Jenis Bangun \\
\hline Atap & Persegi Panjang \\
\hline $\begin{array}{c}\text { Dinding } \\
\text { pada } \\
\text { badan } \\
\text { bagian } \\
\text { samping } \\
\text { kiri pintu }\end{array}$ & & &
\end{tabular}




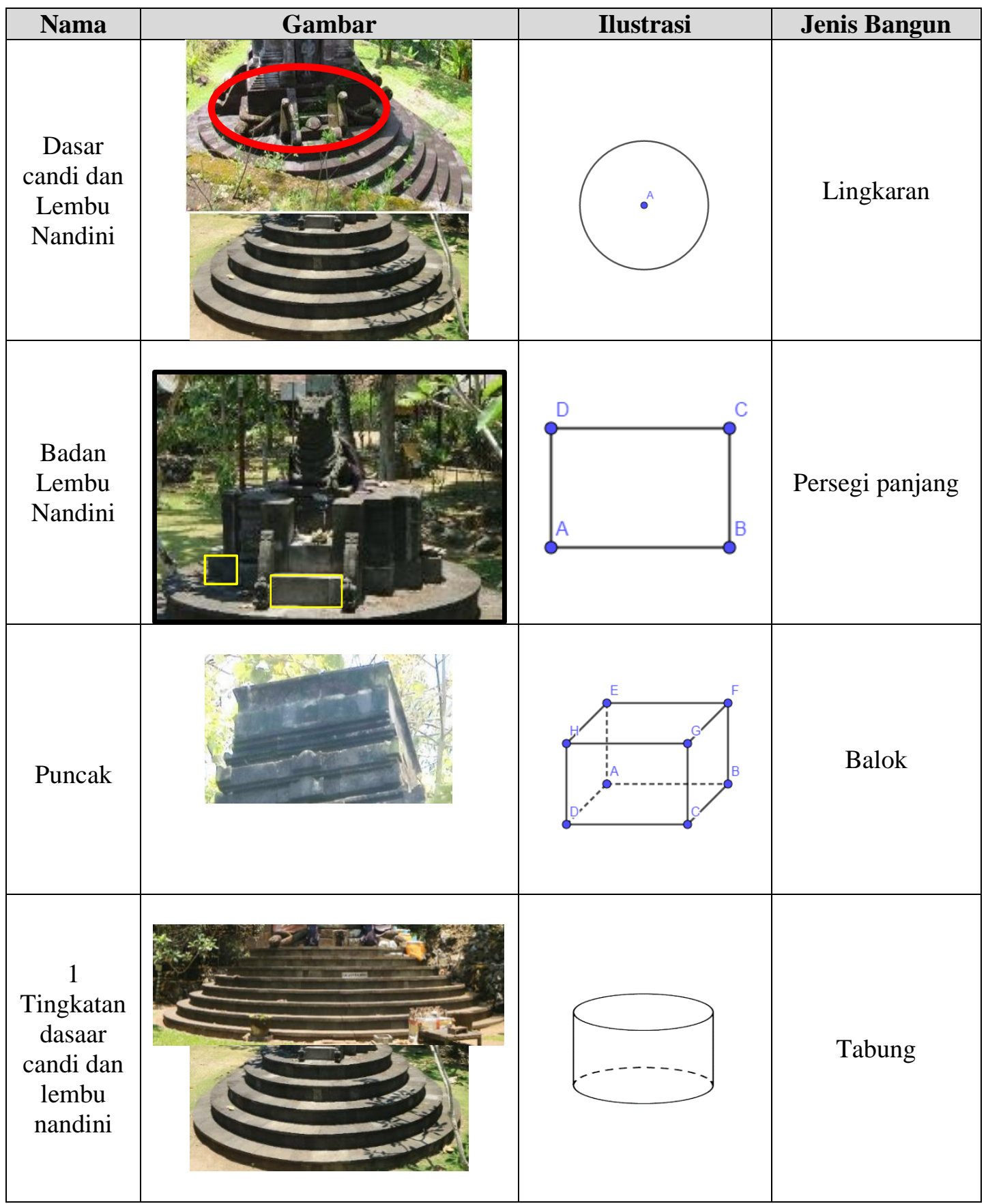

\section{Kesebangunan dan Kekongruenan}

Dua bangun datar (segi banyak) dikatakan sebangun jika sudut-sudut yang bersesuaian memiliki ukuran yang sama dan sisi-sisi yang bersesuaian memiliki proporsi yang sama. Dua bangun dikatakan kongruen jika semua sisi-sisi yang bersesuaian sama panjang dan sudut-sudut yang bersesuaian sama besar dalam (Wahyu, 2018). Candi Agung Gumuk Kancil memiliki unsur kesebangunan terdapat pada tingkatan atap dan dasar yang memiliki bentuk yang sama dengan ukuran berbeda, serta unsur kekongruenan pada ukiran atap candi. 
Tabel 2. Kesebangunan dan Kekongruenan

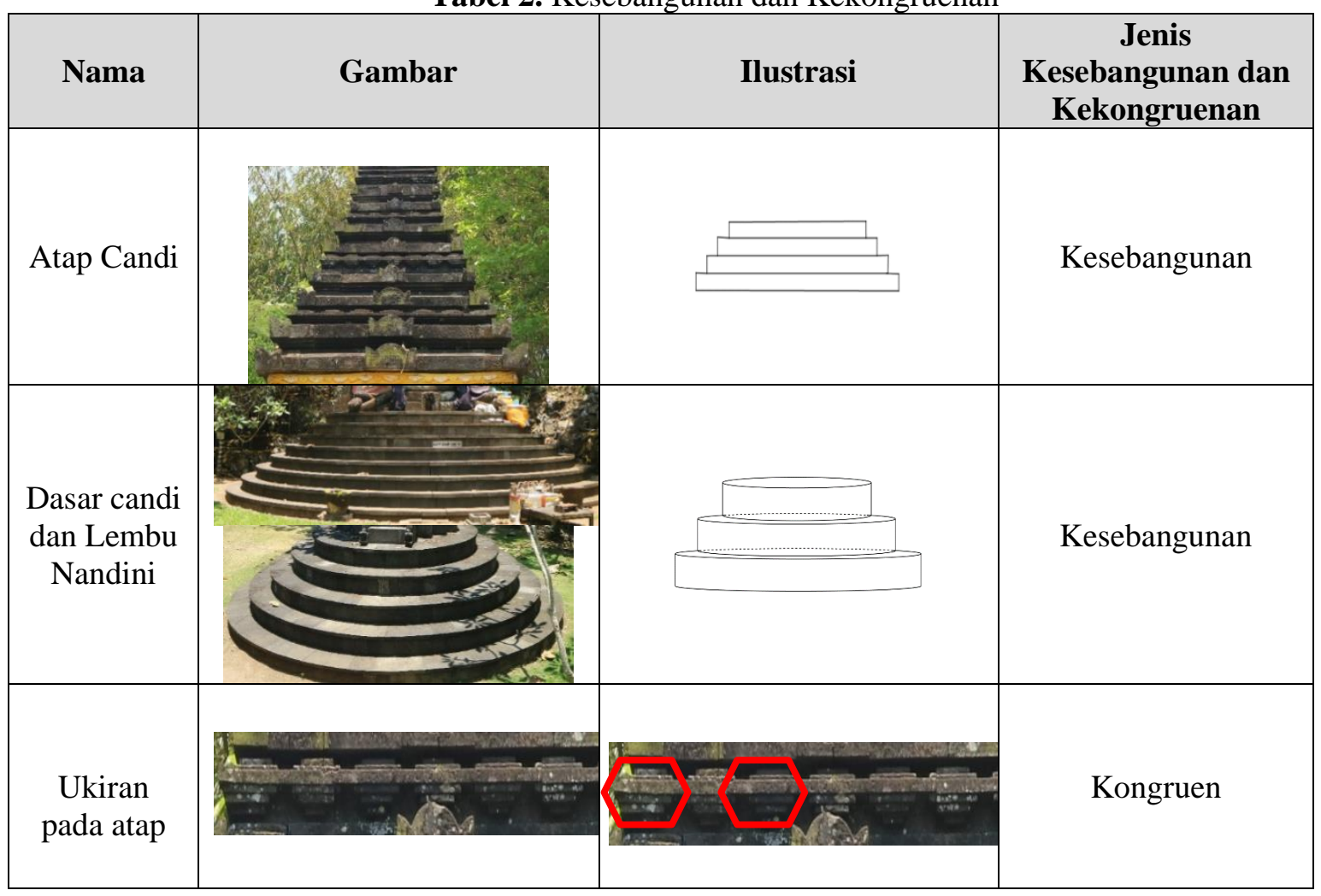

\section{Transformasi Geometri}

Transformasi geometri merupakan salah satu cabang geometri yang membahas tentang perubahan letak atau bentuk dari suatu objek geometri sebagai akibat dari pergeseran, perubahan skala, perputaran. Unsur transformasi geometri terdapat pada ukiran yang terletak pada setiap komponen candi yakni refleksi terhadap sumbu vertikal dan traslasi terhadap sumbu horisontal. Transformasi Geometri yang ditemukan pada penelitian ini yaitu refleksi dan translasi yang disajikan pada Tabel 3.

Tabel 3. Transformasi Geometri

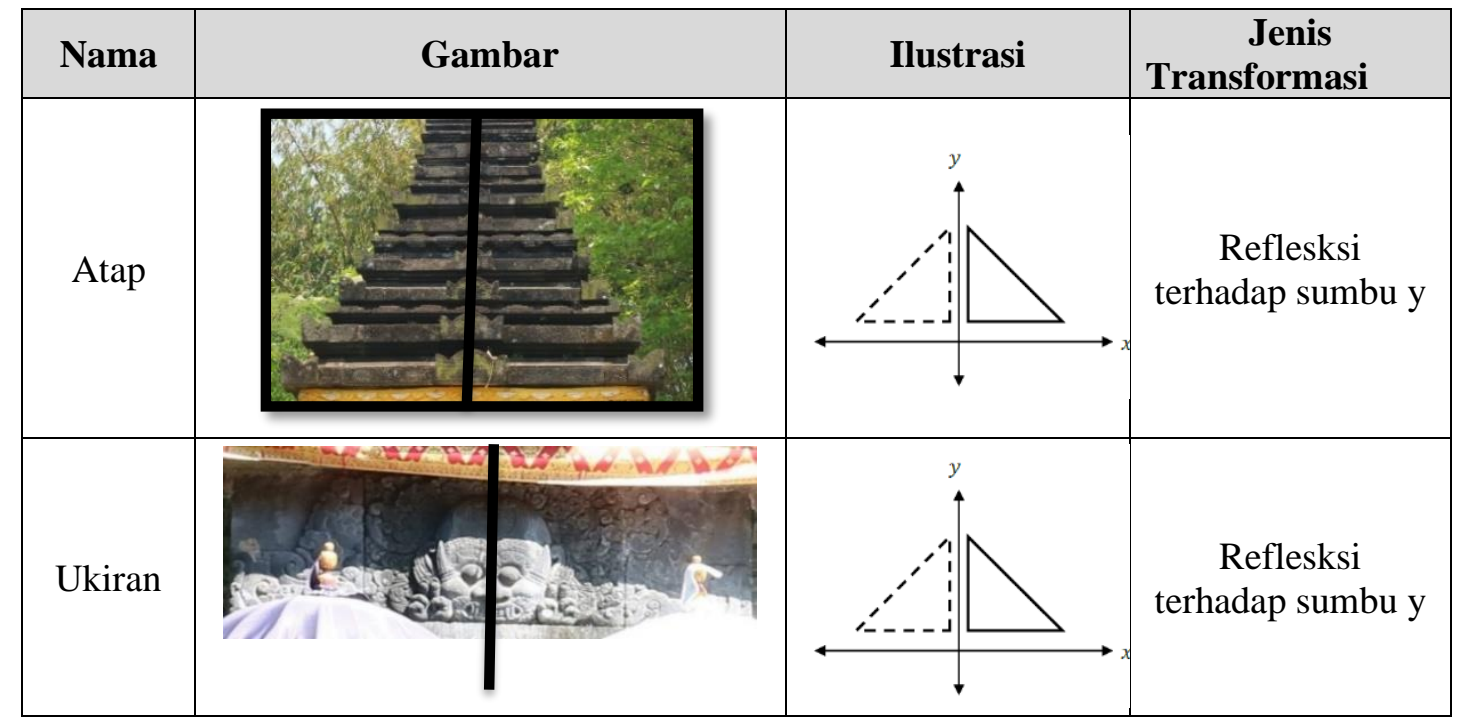




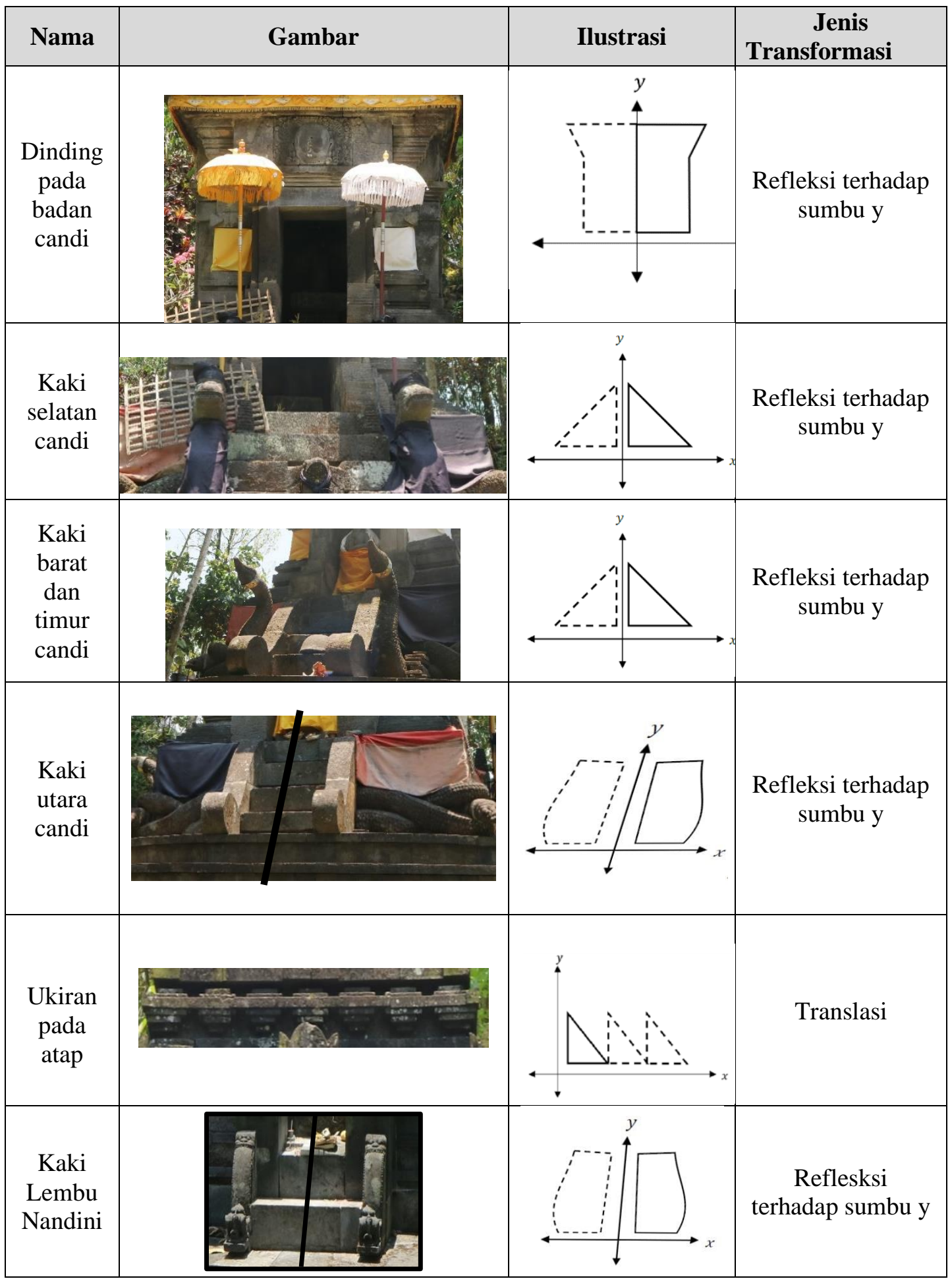

Tranformasi geometri yang ditunjukkan tabel 3 memuat unsur transformasi geometri yaitu refleksi dan translasi. Refleksi yang ditemukan merupakan refleksi sumbu vertikal yang memiliki tingkat refleksi rendah. Hal tersebut sesuai dengan pernyataan Suharta (2017) bahwa dalam membuat sketsa ukiran menggunakan kertas yang dilipat sehingga mendapatkan bentuk ukiran yang sama sebagai elemen refleksi. Ukiran juga dihasilkan oleh salah satu elemen matematika, yang disebut translasi, dengan menggeser pola yang sama terhadap sumbu horisontal. 


\section{Barisan Aritmatika}

Pada bagian tingkatan badan candi memiliki pola ukuran panjang setiap naik satu tingkat ukuran panjangnya akan bertambah beberapa $\mathrm{cm}$ pada bagian kiri dan kanan.Tingkatan pada badan candi memiliki unsur kesebangunan dan dapat membentuk barisan aritmatika dengan rumus suku ke$\mathrm{n}$ adalah $U_{n}=(90+10 n) \mathrm{cm}, n=s u k u k e-i, i=1,2,3, d s t$. Pada bagian dasar candi ukuran diameter memiliki pola ukuran dengan selisih yang sama pada setiap tiap tingkatan. Tingkatan dasar candi memiliki unsur kesebangunan dan dapat membentuk barisan aritmatika dengan rumus suku ke-n adalah $U_{n}=(950-50 n) \mathrm{cm}, n=$ suku $k e-i, i=1,2,3$, dst. Tabel berikut merupakan unsur matematika dalam bentuk barisan aritmatika.

Tabel 4. Barisan Aritmatika

\begin{tabular}{|c|c|c|c|}
\hline Nama & Gambar & Ilustrasi & $\begin{array}{c}\text { Jenis } \\
\text { Barisan } \\
\end{array}$ \\
\hline $\begin{array}{c}\text { Tingkatan } \\
\text { pada } \\
\text { dinding } \\
\text { candi }\end{array}$ & & 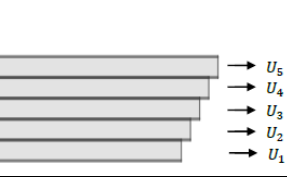 & $\begin{array}{c}\text { Barisan } \\
\text { Aritmatika }\end{array}$ \\
\hline $\begin{array}{c}\text { Dasar } \\
\text { candi dan } \\
\text { Lembu } \\
\text { Nandini }\end{array}$ & & & $\begin{array}{c}\text { Barisan } \\
\text { Aritmatika }\end{array}$ \\
\hline
\end{tabular}

Dari analisis data yang dilakukan, diperoleh informasi bahwa pada setiap komponen candi dan Lembu Nandini memiliki unsur matematika. Sehingga didapatkan informasi bahwa etnomatematika yang ditemukan pada komponen Candi Agung Gumuk Kancil adalah bangun datar, bangun ruang, kesebangunan, kekongruenan, dan transformasi geometri (refleksi dan translasi), dan barisan aritmatika.

Berdasarkan penelitian yang dilakukan etnomatematika pada candi dapat dijadikan sebagai bahan pembelajaran matematika. Bahan pembelajaran matematika tersebut berupa lembar kerja siswa (LKS). Hal ini sebanding dengan penelitian yang telah dilakukan oleh Rahmawati (2019) pada GESIBU Blambangan yang menunjukkan bahwa bangunan tersebut memiliki unsur matematika khususnya geometri yang dapat dijadikan bahan pembelajaran matematika berupa LKS.

Etnomatematika yang diperoleh dalam penelitian ini adalah etnomatematika pada materi bangun datar, bangun ruang, kesebangunan, kekongruenan transformasi geometri (refleksi, translasi, dan rotasi), dan Barisan Aritmatika. Hal ini menunjukkan bahwa menlalui pendekatan etnomatematika diperoleh pemahaman kepada siswa secara detail (Putra et al., 2020; Rachmawati, 2012; Stathopoulou, C., Kotarinou \& Appelbaum, 2015; Wahyuni, 2015). Adapun materi yang akan digunakan pada Lembar Kerja Siswa (LKS) pada materi bangun ruang pada pokok bahasan volume dan luas permukaan tabung untuk kelas IX yang disesuaikan dengan Kurikulum 2013 revisi 2018 terdapat pada silabus matematika tahun 2018. Lembar Kerja Siswa (LKS) dapat dilihat pada https://drive.google.com/file/d/1OUFD NE9QDQEXeHa7UaR1nd1tN5FVm26d/view 


\section{Kesimpulan}

Berdasarkan hasil analisis Candi Agung Gumuk Kancil merupakan bangunan yang terdiri atas tiga bagian yaitu dasar, badan, dan puncak. Pada komplek Candi Agung Gumuk Kancil terdapat bangunan Lembu Nandini dimana secara keseluruhan, bentuk dasar dan bagian atas sama dengan candi induk. Terdapat etnomatematika pada setiap komponen candi yakni pada puncak, badan, kaki, dasar, ukiran dan Lembu Nandini yang terdapat pada setiap komponen candi antara lain, bangun datar, bangun ruang, kesebangunan, kekongruenan, transformasi geometri (refleksi dan translasi), dan barisan aritmatika. Unsur matematika bangun datar terdapat pada setiap komponen candi bagian puncak terdiri dari persegi panjang, badan terdiri dari trapesium, segitiga, segi lima pada dindingnya dan didominasi oleh persegi panjang. Kemudian unsur matematika bangun ruang terdapat pada candi apabila diamati dalam dimensi tiga pada didominasi oleh bangun ruang balok pada atap, bagian badan dan kaki candi didominasi oleh balok, bagian dasar terdiri dari tabung. Unsur kesebangunan terdapat pada tingkatan atap dan dasar yang memiliki bentuk yang sama dengan ukuran berbeda, serta unsur kekongruenan pada ukiran atap candi. Unsur transformasi geometri terdapat pada ukiran yang terletak pada setiap komponen candi yakni refleksi terhadap sumbu vertikal dan traslasi terhadap sumbu horisontal.

Berdasarkan penelitian mengenai etnomatematika pada Candi Agung Gumuk Kancil, maka disarankan untuk menggali lebih dalam mengenai pembuatan bangunan pura untuk mengetahui lebih lengkap bangunan yang memiliki unsur matematika, dapat menggunakan etnomatematika yang telah ditemukan dalam penelitian ini sebagai bahan penelitian pengembangan bahan pembelajaran matematika, dan diharapkan saat melakukan kegiatan wawancara, pertanyaan yang digunakan lebih mendalam agar data yang diperoleh lebih banyak.

\section{Daftar Pustaka}

Asnawati, S., \& Dewi, I. L. K. (2019). Pemahaman Konsep Geometri dan Self Confidence Mahasiswa Calon Guru Matematika pada Mata Kuliah Pembelajaran Mikro untuk Persiapan Pelaksanaan PPL Di Sekolah. Journal of Medives: Journal of Mathematics Education IKIP Veteran Semarang, 3(1), 75. https://doi.org/10.31331/medivesveteran.v3i1.706

Putra, R. Y., Wijayanto, Z., \& Widodo, S. A. (2020). Etnomatematika: Masjid Soko Tunggal Dalam Pembelajaran Geometri 2D. Jurnal Riset Pendidikan Dan Inovasi Pembelajaran Matematika (JRPIPM). https://doi.org/10.26740/jrpipm.v4n1.p10-22

Rahmawati, E. (2019). Etnomatematika pada Gapura Gesibu Blambangan Sebagai Bahan Pembelajaran Matematika. Skripsi, 1-19.

Rachmawati, I. (2012). Eksplorasi etnomatematika masyarakat sidoarjo. Ejournal Unnes, 18.

Rani. (2018). Etnomatematika pada candi ratu boko sebagai pendukung pembelajaran matematika realistik. Prosiding Seminar Nasional Pendidikan, (April), 1-18.

Stathopoulou, C., Kotarinou, P., \& Appelbaum, P. (2015). Ethnomathematical research and drama in education techniques: developing a dialogue in a Geometry class of 10th grade students. Revista Latinoamericana de Etnomatemática, 8(2), 105-135. https://doi.org/10.1021/am502675c

Suharta, I. G. P., Sudiarta, I. G. P., \& Astawa, I. W. P. (2017). Ethnomathematics of Balinese Traditional Houses. International Research Journal of Engineering, IT \& Scientific Research, $3(4), 42$.

Wahyu, S., Setiawan, T. B. S. (2018). Etnomatematika pada Pura Mandara Giri Semeru Agung 
Sebagai Bahan Pembelajaran Matematika. Kadikma, 9(1), 156-164.

Wahyuni, I. (2015). Eksplorasi etnomatematika masyarakat sidoarjo. Fenomena (Jurnal Penelitian Islam Indonesia), 15(2), 225-238.

Wahyuni, A., Aji, A., Tias, W., dan Sani, B. (2013). Peran Matematika dalam Membangun Karakter Bangsa. November, 978-979,2013.

Zuhry, A. W. (2018). Artikel Studi Tentang Candi Mirigambar Di Tulungagung. Universitas Nusantara PGRI Kediri Surat Pernyataan Artikel Skripsi Tahun 2018. 02(04). 